\title{
BMJ Open Description of the BRIGHTLIGHT cohort: the evaluation of teenage and young adult cancer services in England
}

\author{
Rachel M Taylor, ${ }^{\oplus 1}$ Lorna A Fern, ${ }^{2}$ Julie Barber, ${ }^{3}$ Javier Alvarez-Galvez, ${ }^{4}$ \\ Richard Feltbower, ${ }^{5}$ Stephen Morris, ${ }^{6}$ Louise Hooker, ${ }^{7}$ Martin G McCabe, ${ }^{8}$ \\ Faith Gibson, ${ }^{9,10}$ Rosalind Raine, ${ }^{11}$ Dan P Stark, ${ }^{12}$ Jeremy S Whelan ${ }^{\odot 2}$
}

To cite: Taylor RM, Fern LA, Barber J, et al. Description of the BRIGHTLIGHT cohort: the evaluation of teenage and young adult cancer services in England. BMJ Open 2019:9:e027797. doi:10.1136/ bmjopen-2018-027797

- Prepublication history and additional material for this paper are available online. To view these files, please visit the journal online (http://dx.doi. org/10.1136/bmjopen-2018027797).

Received 7 November 2018 Revised 8 February 2019 Accepted 12 February 2019

Check for updates

(C) Author(s) (or their employer(s)) 2019. Re-use permitted under CC BY-NC. No commercial re-use. See rights and permissions. Published by BMJ.

For numbered affiliations see end of article.

Correspondence to

Dr Lorna A Fern;

lorna.fern@nhs.net

\section{ABSTRACT}

Objective International recognition of the unique needs of young people with cancer is growing. Many countries have developed specialist age-appropriate cancer services believing them to be of value. In England, 13 specialist principal treatment centres (PTCs) deliver cancer care to young people. Despite this expansion of specialist care, systematic investigation of associated outcomes and costs has, to date, been lacking. The aim of this paper is to describe recruitment and baseline characteristics of the BRIGHTLIGHT cohort and the development of the bespoke measures of levels of care and disease severity, which will inform the evaluation of cancer services in England. Design Prospective, longitudinal, observational study. Setting Ninety-seven National Health Service hospitals in England.

Participants A total of 1114 participants were recruited and diagnosed between July 2012 and December 2014: 55\% $(n=618)$ were men, mean age was 20.1 years $(S D=3.3)$, most $(86 \%)$ were white and most common diagnoses were lymphoma (31\%), germ cell tumour (19\%) and leukaemia (13\%).

Results At diagnosis, median quality of life score was significantly lower than a published control threshold (69.7 points); $40 \%$ had borderline to severe anxiety, and $21 \%$ had borderline to severe depression. There was minimal variation in other patient-reported outcomes according to age, diagnosis or severity of illness. Survival was lower in the cohort than for young people diagnosed during the same period who were not recruited (cumulative survival probability 4 years after diagnosis: $88 \%$ vs $92 \%$ ).

Conclusions Data collection was completed in March 2018. Longitudinal comparisons will determine outcomes and costs associated with access/exposure to PTCs. Findings will inform international intervention and policy initiatives to improve outcomes for young people with cancer.

\section{INTRODUCTION}

BRIGHTLIGHT is a programme of research that aims to determine whether specialist care for teenagers and young adults (TYA) with cancer is associated with improved outcomes. The National Institute for Health and Clinical Excellence (NICE) outlined in the Improving Outcomes Guidance for Children and Young People

\section{Strengths and limitations of this study}

- A cohort of teenagers and young adults with newly diagnosed cancer was established with the involvement of young people in planning and operation that contributed to a high rate of retention.

- The sociodemographic characteristics of the cohort are broadly similar to the contemporary teenage and young adult cancer population, supporting the generalisability of results.

- Data have been collected from multiple sources including patients, individual clinical care records and established National Health Service datasets.

- The study recruited a smaller proportion of young people diagnosed with cancer in the available time period, resulting in lower statistical power to address the impact of heterogeneity.

- A metric developed to quantify specialist care may not be sensitive enough to reflect the complexity of specialist care and individual patient pathways.

with Cancer, ${ }^{1}$ a model of specialised care based on a limited number of hospitals designated as principal treatment centres (PTCs). At that time, minimal information was available about either the constituent parts of such specialist care or the benefits that might accrue from it and why. BRIGHTLIGHT comprises six interlinked projects centred on a prospective, longitudinal cohort of young people recruited soon after a diagnosis of cancer that examines their outcomes and experiences of cancer care. Additional studies address elements of specialisation; the environment of care $^{23}$; the competencies desirable in healthcare professionals delivering specialist care ${ }^{4}$; a metric to quantify specialist care; caregiver's experience of care; and a health economic analysis to determine the cost of specialist care. The programme has been underpinned by an extensive patient and public involvement strategy. ${ }^{5-9}$

Cancer in young people is uncommon, accounting for less than $1 \%$ of all new cancer diagnoses in England. ${ }^{10}$ Despite its rarity, 
cancer is the second leading cause of death for young people, accounting for $11 \%$ of deaths in those aged 15-24 years. ${ }^{11}{ }^{12}$ In addition, a number of issues argue for special attention for young people with cancer and for robust evidence to support current and future healthcare policies. For example, young people present with a spectrum of cancer types that is distinct from those affecting younger children and older adults. ${ }^{11} \mathrm{~A}$ cancer diagnosis during adolescence and young adulthood has an acute and unique impact on this critical and complex stage of life development, disrupting physical health, social and educational goals as well as psychological well-being. ${ }^{13}$ These factors have additional importance when considered against the advantages that accrue to society from the successful treatment through the prolonged fulfilment of their contribution in employment and other societal impacts. ${ }^{14}$

While most young people are cured, outcomes for some cancers have not improved in line with those achieved for children and older adults. ${ }^{15}$ There exists a general consensus among healthcare professionals that the needs of young people are poorly met by cancer services that are tailored towards the needs of children and older adults. ${ }^{16}$ Young people fall between child and adult cancer services into what has been described as either 'the grey zone ${ }^{, 17}$ or 'no man's land'. ${ }^{18}$ Prolonged routes to diagnosis, unfavourable tumour biology with increasing age, limited access to clinical trials, lack of compliance with treatment protocols, inconsistent use of molecular diagnostics that may assist with optimal care and a lack of specialist supportive care have all been implicated in the short fall in survival improvements. ${ }^{19-28}$

Young people themselves have described unsatisfactory experiences of care that include: lack of recognition of their autonomy; failure to facilitate them to meet normal life goals during treatment; lack of peer support; care by staff with little experience of young people; and finally, inappropriate care environments. ${ }^{92-31}$ The inability of traditional healthcare silos to meet the unique psychosocial and healthcare needs of this specific population is increasingly highlighted. ${ }^{32-34}$ Place of treatment and delivery of cancer care, in terms of both disease and age-appropriate specialist settings, is increasingly acknowledged as potentially significant to the outcomes for young people with cancer. ${ }^{3536}$

To address these unique needs and deficit in outcomes' knowledge, in August 2005 the NICE Improving Outcomes Guidance recommended that all care for patients under 19 must be provided in age-appropriate facilities and those aged 19 and over should have 'unhindered access to age-appropriate facilities and support when needed'. To accommodate this recommendation, 13 TYA PTCs were identified across England. Key components of the services of the TYA PTC encompass tumour site-specific expertise delivered in conjunction with meeting the broader psychosocial needs of young people to support successful navigation of critical life transitions. This is directed through the TYA multidisciplinary team (MDT). ${ }^{1}$
However, despite national guidance supporting this approach to the delivery of cancer care for young people aged 15-24 years, ${ }^{1}$ around half of young people continue to be treated in children's and adult cancer units with no or limited access to the TYA PTC, many receiving care in hospitals 'designated' by National Health Service (NHS) commissioners to provide elements of specialist care that are available in a TYA PTC.

The aim of the BRIGHTLIGHT programme of research is to evaluate the benefit of specialist TYA cancer services for young people aged 13-24 years. The study has four key objectives specific to the cohort:

1. Relate the proportion of care young people received in a TYA PTC to: quality of life, satisfaction with care, clinical processes and clinical outcomes.

2. Examine young people's experience of cancer care through a longitudinal descriptive survey.

3. Compare social and educational milestones among young people receiving different levels of TYA cancer care.

4. Determine the costs of specialist care to young people, their families and the NHS.

\section{Objectives}

The aim of this paper is to describe the complex recruitment process for establishing the BRIGHTLIGHT cohort, to provide details of bespoke measures of levels of care and disease severity that were developed to inform the analysis of the evaluation and to describe the baseline characteristics of the cohort.

\section{STUDY DESIGN}

The BRIGHTLIGHT cohort is a prospective longitudinal cohort study, obtaining data through a bespoke survey, administered through face-to-face interview, telephone interview and online, five times over 3 years: $5-7$ months after diagnosis then at 12, 18, 24 and 36 months. ${ }^{37}$

\section{PATIENT AND PUBLIC INVOLVEMENT}

The focus of this study was identified by young people as a priority area for research. BRIGHTLIGHT was preceded by a period of feasibility work where we worked with young people as coresearchers to develop the research questions, outcome measures and study design. ${ }^{69}$ The study has a Young Advisory Panel who have worked with us since 2011 and who have been integral in naming the study, ${ }^{5}$ study management, ${ }^{78}$ identifying other areas for research $^{38}$ and dissemination. ${ }^{39}$

\section{SAMPLE AND SETTING}

\section{Participants}

The BRIGHTLIGHT cohort included young people aged 13-24 years, newly diagnosed with cancer (International Classification of Diseases, 10th Revision codes C00-C97) in an English hospital and recruited within 4 months of 
diagnosis. Eligibility criteria were as inclusive as possible so no restriction according to language or a sensory impairment that affected communication was applied. The only exclusion criteria were: young people receiving a custodial sentence; if the young person was not anticipated to be alive at the first point of data collection (6 months after diagnosis); and recurrence of a previous cancer or they were not capable of completing a survey, for example, sedated and in intensive care.

\section{Recruitment}

Young people present with a wide range of cancer diagnoses. ${ }^{11}$ It was anticipated that to identify and recruit potentially eligible patients would be the biggest challenge because of: (1) low incidence; (2) presenting to numerous points in healthcare system, due to age and multiple diagnostic subtypes; and (3) inconsistent referral pathways for tertiary care. The NICE guidance was issued in $2005,{ }^{1}$ and by 2010 , only $40 \%$ of newly diagnosed young people were known to a TYA MDT based at a PTC. ${ }^{40}$ Analysis of the national cancer datasets between 2010 and 2011 indicated that young people were being treated in an additional 133 hospitals across England. Thus, to capture the full cohort of young people, we needed to open recruitment in as many hospitals as possible, have a mechanism to identify young people across the country and also have access to an extensive network of researchers to recruit and administer the study questionnaires.

There were two mechanisms for identifying young people: first through the national cancer waiting times dataset, which has been reported in detail previously. ${ }^{41}$ This is routinely collected NHS data used to monitor diagnostic and treatment targets; feasibility work suggested young people could be identified within 3 months of diagnosis. ${ }^{42}$ However, when this method was applied nationally, it was found to be neither timely nor accurate so a second mechanism was introduced: principal investigators were asked to liaise with the coordinators of all tumour-specific MDTs (except prostate cancer) so the person managing recruitment to the study could be informed of new diagnoses in young people aged 13-24 years. A third method to directly approach young people to invite them to participate was also introduced in the later stages of recruitment but did not significantly impact on accrual. ${ }^{43}$

The second challenge was working with a large number of hospitals, of which most were likely to identify a few eligible patients over the course of the study and who might present to one of several departments. BRIGHTLIGHT opened to recruitment in 109 hospitals, of whom 97 identified and recruited between 1 and 106 (median 5) young people per hospital, 12 not recruiting any participants. England has a national network of research personnel funded by the National Institute for Health Research (NIHR), tasked with facilitating recruitment into clinical studies. ${ }^{41}$ The aim was to recruit 2012 young people diagnosed between July 2012 and December 2013. Despite making multiple targeted amendments to the protocol and iteratively working with NIHR researchers and the TYA healthcare professional community to increase the proportion of patients who were offered study entry (online supplemental file 1), recruitment was slower and lower than anticipated. In April 2014, an extension to recruitment until April 2015 was approved (young people diagnosed until December 2014, recruited within 4 months of diagnosis), and a lower target sample size was agreed (figure 1).

\section{METHODS}

Data were collected from three sources: young people, patient medical records and central NHS and Public Health England databases.

\section{Data from young people}

Patient-reported outcomes were collected from young people at five time points over 3 years: $4-7$ months after diagnosis (wave 1), 12 months (wave 2), 18 months (wave 3 ), 2 years (wave 4 ) and a final data capture 3 years after diagnosis (wave 5). Data were collected using a study-specific questionnaire, the BRIGHTLIGHT Survey ${ }^{37}$ (available under licence from https://xip.uclb.com/i/ healthcare_tools/brightlight_wave1.html), which was administered as a face-to-face interview in young people's homes at wave 1 . Subsequent waves were administered online or through telephone interviews. At wave 1, young people also completed study-specific health economics questionnaires, described below.

\section{The BRIGHTLIGHT Survey}

The BRIGHTLIGHT Survey is an investigator and young person-designed self-report questionnaire that was administered through computer-assisted personal or telephone interview or online by an independent research organisation. It was developed using patient-experience literature ${ }^{44}$ and was underpinned by a conceptual framework to guide question content. ${ }^{9}$ The BRIGHTLIGHT Survey contains five validated outcome measures and questions to reflect young people's experience of diagnosis and cancer care (table 1). ${ }^{37}$ Completion of treatment occurs at different time points according to diagnosis. During the feasibility work, young people emphasised that they did not want to be asked questions about cancer when treatment ended and therefore the computer administration of the BRIGHTLIGHT Survey had complex routing to ensure young people were only asked questions that were relevant to their current situation. ${ }^{37}$ For example, questions related to prediagnosis and diagnostic experience were only asked at wave 1. The BRIGHTLIGHT Survey also used 'pull through' options so that participants could reflect on responses given in previous waves before answering. For example, questions about employment/education goals were tailored so participants could be asked again at wave 5 to ascertain if goals had changed and if this was cancer influenced.

\section{Health economics questionnaires}

Cancer/treatment-related costs incurred by young people and families were collected using a study-specific 


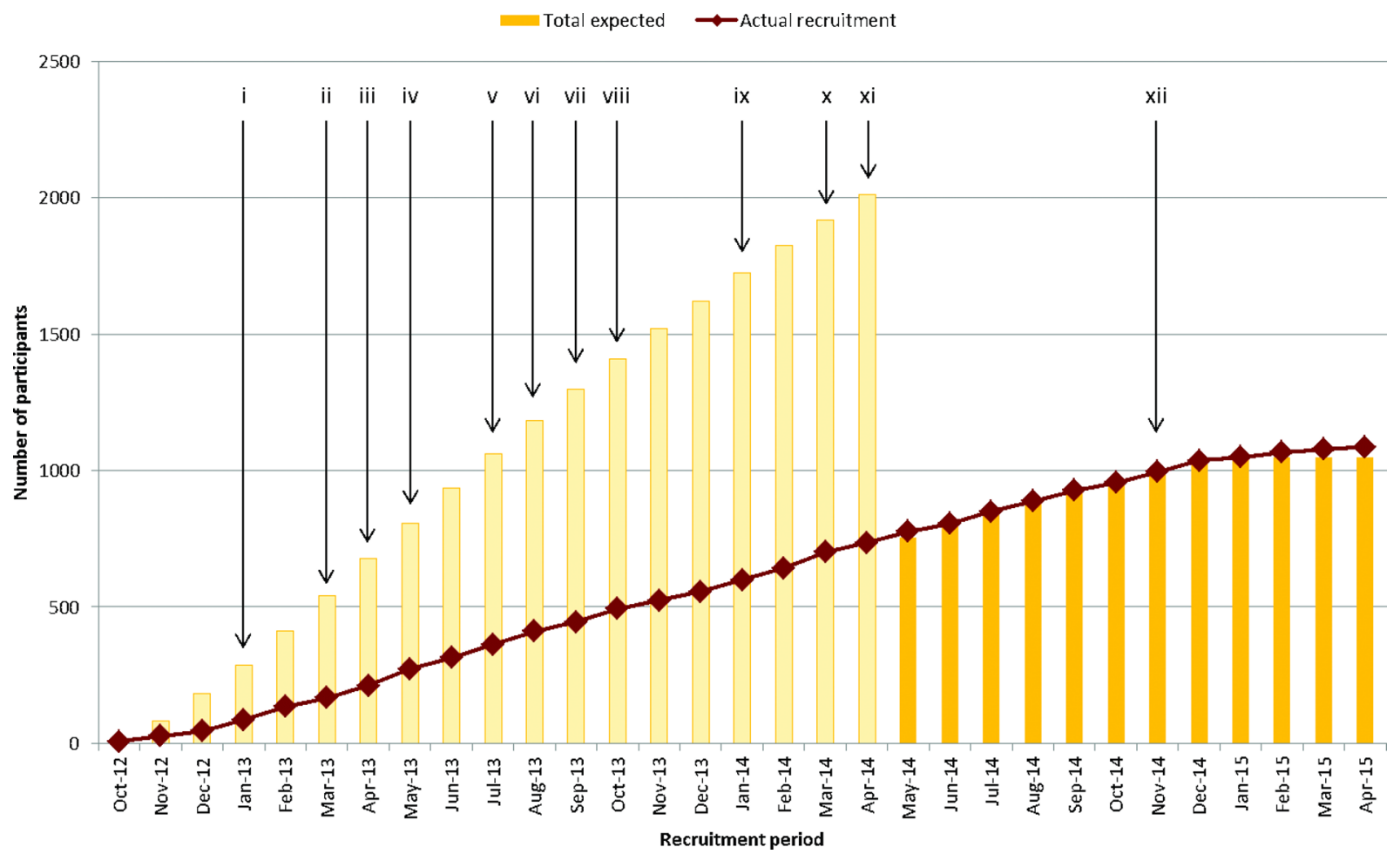

Figure 1 Summary of actions undertaken to improve recruitment and impact on accrual figures. (i) Open to most Trusts agreeing to participate ( $n=77$ ); posters to advertise BRIGHTLIGHT distributed to all Trusts. (ii) Information to all newly diagnosed young people distributed in CLIC Sargent information packs; top recruiters reported in the TYAC weekly bulletin (Teenage and Young Adults with Cancer the professional organisation in the UK supporting healthcare professionals with teenagers and young adults with cancer). (iii) Healthcare professional information leaflets sent to all Trusts (hard copy and electronic for local distribution). (iv) Director/assistant directors of the National Cancer Research Network emailed all the Cancer Network Managers directing them to make recruitment to BRIGHTLIGHT a priority; approved amendment to allow consent to be taken at the same time as giving the information sheet. (v) Review of screening logs and site-specific feedback presentations sent to each principal treatment centre (PTC). (vi) Open to recruitment in all 13 PTCs. (vii) Approval to use social media to recruit young people; open in all 109 Trusts agreeing to open to recruitment. (viii) Attendance at a Teenage Cancer Trust Lead Nurse event to highlight recruitment issues and gain support. (ix) Emails sent by universities (communication teams or student unions) to current students with a link to the website to capture young people continuing with education after diagnosis; training for Youth Support Coordinators to be able to recruit young people. (x) Attend a CLIC Sargent Social Worker event to promote the study and gain support to take a recruitment role. (xi) Information on the BRIGHTLIGHT website in video format. (xii) Recruitment method based on the National Cancer Patient Experience Survey implemented.

Cost of Care Questionnaire and Cost Record. These included questions regarding: travel (car parking, petrol and capital depreciation, and public transport); time off work; medical equipment use; prescription and overthe-counter drug use; cost of accommodation incurred through hospitalisation; complementary; and cost of family care for siblings. The Cost of Care Questionnaire was administered at wave 1 and required young people and their families to record costs incurred from the above items retrospectively since diagnosis. The Cost Record was given at waves 1 and 2, requesting the same information collected prospectively on a weekly basis.

\section{Data from medical records}

Research teams who recruited young people completed an electronic case report form (CRF) 12 months after diagnosis, which contained key variables relating to diagnosis, treatment, clinical process and outcome variables. This included postcode at the time of diagnosis, locations of care, details of diagnosis, MDT treatment planning and care, and outcomes at 12 months after diagnosis. The Index of Multiple Deprivation (IMD) is a measure of socioeconomic status ${ }^{45}$ and was derived from the postcode at diagnosis, based on the population denominator of England. Clinical processes of care were defined as documentation of:

1. Histological diagnosis.

2. Molecular diagnosis.

3. Cancer stage or prognostic group.

4. Initial treatment plan.

5. Evidence of multidisciplinary communication.

6. Assessment by supportive care services, defined as documented contact with a clinical nurse specialist plus one other member of the MDT (social worker, youth support coordinator, counsellor, psychologist, dietitian, physiotherapist and occupational therapist).

7. Fertility discussion.

8. Consideration for inclusion in a clinical trial. 
Table 1 Summary of the content of the BRIGHTLIGHT Survey

\section{Construct and questionnaire Details}

Quality of life: Pediatric Quality of Contains 23 items scored on a 5-point Likert scale.

Life Questionnaire ${ }^{60}$

Four domains: physical, emotional, social and work/school functioning.

Two summary scores (physical and psychosocial function) and a total score.

Domain, summary and total scores on 0-100 scale, with 100 representing the best

possible quality of life.

Scores $<69.7$ indicate a high risk of impaired quality of life. ${ }^{48}$

Health status: EuroQol-5 Dimension Comprises five dimensions (mobility, self-care, usual activities, pain/discomfort and 3 level $^{73}$

anxiety/depression) scored on three levels (no, some and severe problems).

The EQ-5D visual analogue scale records self-reported health on a vertical scale ranging from 'best imaginable health state' to worst imaginable health state'.

Scores $0-1$ with 0 representing death and 1 representing perfect health (negative scores represent a health state worse than death).

\section{Anxiety and depression: Hospital Anxiety and Depression Scale ${ }^{74}$ \\ A measure of depression and anxiety. \\ Contains 14 items, scored on a four-grade scale (0-3). Summary scores for depression and anxiety (ranging from 0 to 21). \\ Scores of 8-10 are defined as borderline and 11 and over are considered moderate/ severe anxiety and depression. ${ }^{51}$ \\ Social support: Multidimensional Scale of Perceived Social Support ${ }^{52}$ \\ Scores for support by friends, family and significant others plus total support score. \\ Contains 12 statements, rated on 7-point Likert scale. \\ Total support score is an average ranging from 1 to 7 ; subsupport scores range 4-28. \\ Total scale score 1-2.9 are considered low support; a score of 3-5 is considered moderate support; and scores from 5.1 to 7 are considered high support.}

\begin{tabular}{|c|c|}
\hline $\begin{array}{l}\text { Illness perception: The Brief Illness } \\
\text { Perception Scale }{ }^{75}\end{array}$ & $\begin{array}{l}\text { Measures the emotional and cognitive representations of illness. } \\
\text { Contains eight* questions with fixed response scale specific for each question, for } \\
\text { example, not at all to extremely helpful. } \\
\text { Each question represents a different dimension of illness perception: consequence, } \\
\text { personal control, treatment control, timeline, identity, coherence, emotional } \\
\text { representation and concern. Responses scored } 1-10 \text {, the higher the score, the greater } \\
\text { perceived illness impact. } \\
\text { No overall score and each question represents a single domain. }\end{array}$ \\
\hline Cancer experience questions ${ }^{37}$ & $\begin{array}{l}\text { Comprises } 12 \text { experience domains: prediagnosis experience, diagnostic experience, } \\
\text { place of care, contact with healthcare professionals, treatment experience, fertility, } \\
\text { involvement in clinical trials, adherence, communication and coordination of care, } \\
\text { education, employment, well-being and relationships. } \\
\text { Total of } 238 \text { questions with question-specific responses describing experience. }\end{array}$ \\
\hline
\end{tabular}

${ }^{*}$ Timeline statement not included.

\section{Data from national datasets}

Data from National Cancer Registration and Analysis Service (NCRAS) and Hospital Episode Statistic (HES) were used to supplement and validate details of treatment received in the TYA PTC, to support a detailed health economic evaluation based on hospital attendance and healthcare received and to cross-check against the electronic CRF. NCRAS data included date of diagnosis, tumour morphology, staging and treatment data; and HES data included dates for admitted patient care, outpatient and accident and emergency attendance, plus receipt of chemotherapy and radiotherapy.

\section{DEVELOPMENT OF BESPOKE METRICS}

\section{Defining levels of care}

BRIGHTLIGHT aims to evaluate exposure to specialist TYA cancer services, defined as treatment in the TYA PTC. In recognition that patients may receive elements of care in more than one hospital, we proposed that care could be categorised by three levels according to the proportion of care received in a TYA PTC. To accurately allocate cohort participants to the appropriate level of care, analysis of HES data were used. In summary, PTC Trust codes were identified for 2012-2014 and applied to HES data so the proportion of days spent in a TYA PTC in the first 6 months and 12 months after diagnosis could be calculated (details provided in online supplemental file 2).

\section{Defining severity of illness}

Advanced cancer is associated with poorer quality of life. ${ }^{46}$ We planned to compare quality of life of those treated in different care environments. To do so, we needed to consider ways to control for differences between patients that might influence this outcome and, in particular, the severity of their cancer. However, this is difficult for TYA as they present with a heterogeneous array of malignancies. ${ }^{11}$ While most cancers have staging 
Table 2 BRIGHTLIGHT severity of illness index (see online supplemental file 3)

\begin{tabular}{|c|c|c|c|}
\hline Cancer type ${ }^{11}$ & Least severe & Intermediate severity & Most severe \\
\hline Leukaemias & CML. & ALL; other and unspecified. & AML. \\
\hline
\end{tabular}

\begin{tabular}{|c|c|c|}
\hline Hodgkin's lymphoma & All stages. & \\
\hline $\begin{array}{l}\text { Central nervous system } \\
\text { tumours }\end{array}$ & $\begin{array}{l}\text { Pituitary adenomas (D35.2); } \\
\text { subependymal giant cell } \\
\text { astrocytoma (C43.2). }\end{array}$ & $\begin{array}{l}\text { Other completely resected } \\
\text { WHO grade I tumours for } \\
\text { which surgery is the only } \\
\text { treatment needed, except } \\
\text { craniopharyngiomas. }\end{array}$ \\
\hline
\end{tabular}

Craniopharyngiomas; incompletely resected or unresectable grade I tumours; all grade II-IV tumours, any needing radiotherapy or chemotherapy. This includes ependymomas, medulloblastomas and intracranial GCTs.

\begin{tabular}{ll}
\hline Bone tumours & $\begin{array}{l}\text { Surgery only (low grade, } \\
\text { periosteal and parosteal). }\end{array}$ \\
\hline $\begin{array}{l}\text { Soft tissue sarcoma } \\
\text { Rhabdomyosarcoma }\end{array}$ & $\begin{array}{l}\text { Stages 1-2. } \\
\text { Low risk EpSSG A-D. }\end{array}$ \\
\hline Stanoma & Stages 1-2 (except 2c). \\
\hline Carcinoma & $\begin{array}{l}\text { All thyroid; all stage 1; Cervix } \\
\text { stage unknown. }\end{array}$
\end{tabular}

Miscellaneous and unspecified
All other.

\section{Stage 4.}

All others; unknown.

Stage 2c; stage 3 (except 3c); Stage 3c; stage 4. stage unknown.

Stages 2-3; all nasopharyngeal; stage unknown (except cervix).

Stage 4.

All.

ALL, acute lymphoblastic leukemia; AML, acute myeloid leukemia; CML, chronic myeloid leukemia; EpSSG, European Paediatric Soft Tissue Sarcoma Study Group; GCT, germ cell tumours; ICD-10, International Classification of Diseases, 10th Revision.

criteria that differentiate between more or less extensive disease (typically groups 1-4 in ascending order of worsening survival), stage is not directly comparable between cancer types, and a comparison based purely on staging would be meaningless due to the variation in outcomes between different cancers allocated to the same stage level. For example, stage 4 thyroid cancer is associated with a much higher chance of survival than, say, stage 4 bowel cancer. Furthermore, survival alone is not a good indicator of severity of illness as it takes no account of disease and treatment morbidity both for the short and long term. We therefore developed a bespoke 'severity' grading system to include symptom and treatment burden as well as predicted survival and burden of late effects. Each cancer type was graded as least, intermediate and most severe based on cancer-specific information thus allowing comparisons between groups of patients with multiple types of cancer (table 2; detailed methodology is presented in online supplemental file 3).

\section{Analysis}

The number of young people at each stage of the project were described using a flow diagram, including the numbers eligible, consenting to be involved and followed up at each survey point. Reasons for non-participation at each stage were summarised. Potentially eligible patients who did not participate in the cohort study were compared against those who consented with regard to age, gender, ethnicity, location (based on the network linked to each PTC) and diagnosis. Data in both groups were summarised as means with $\mathrm{SD}$, medians with IQRs or frequency and percentage $(\%)$, as appropriate and comparisons made using standard $\chi^{2}$ and t-tests. Since sample sizes for these comparisons were very large, statistical significance is defined as $\mathrm{p}<0.001$.

Survival from diagnosis was summarised using KaplanMeier plots, and the cohort and non-cohort groups were compared using Cox regression to adjust for age, gender, ethnicity, location and type of cancer. Patient-reported outcomes collected in the first wave were scored according to published guidance for each of the validated measures. The characteristics of the cohort were summarised using means/medians (SD/IQR) or frequency $(\%)$ as appropriate.

\section{RESULTS}

A total of 1126 young people were recruited for whom valid consent was available from 1114 (figure 2). 


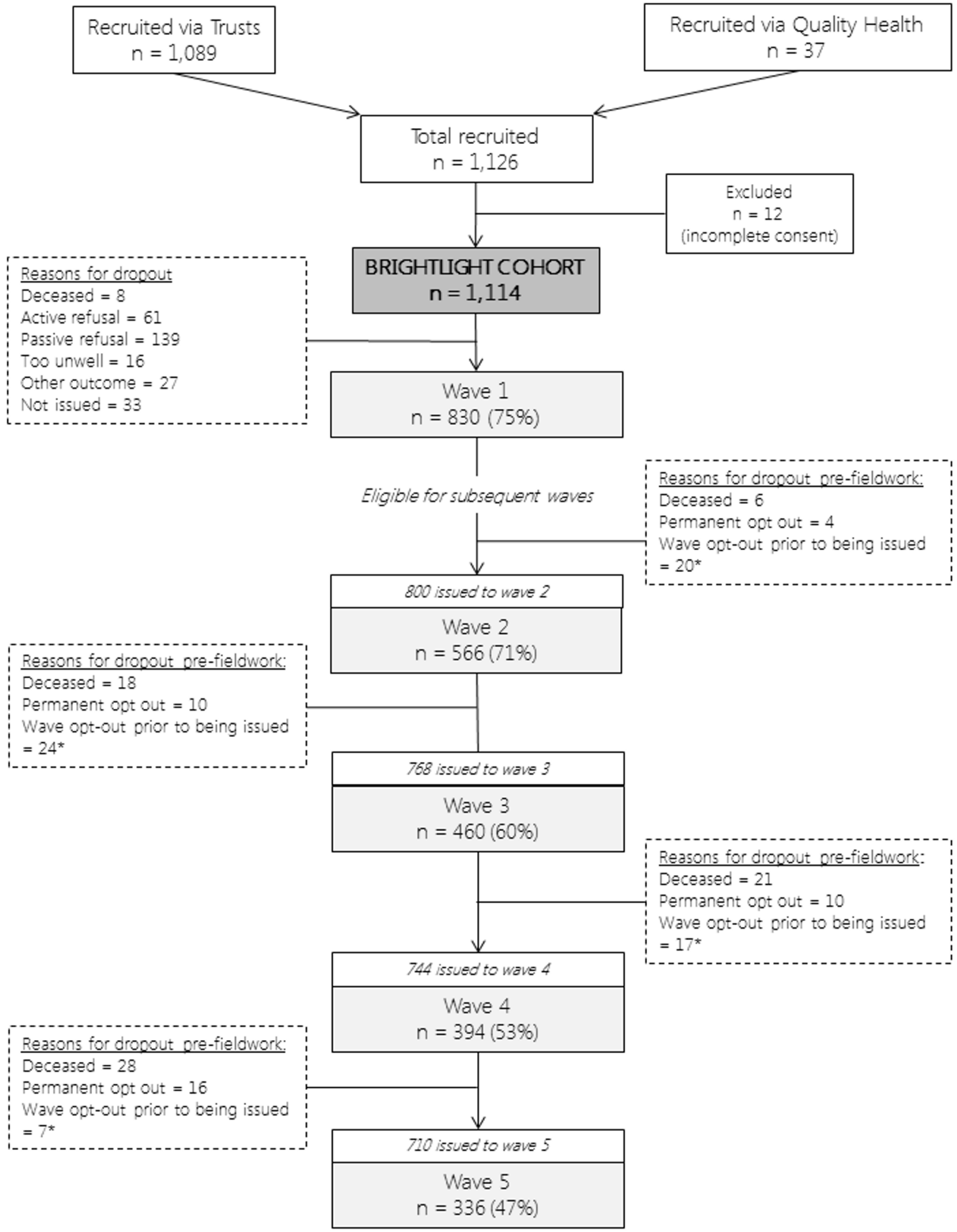

Figure 2 A summary of participation at each wave of data collection. *Drop-outs between waves due to death, permanent optout or wave opt-out. Wave opt-outs prior to being issued were not permanent opt-outs; participants could opt-out of a single wave but participate in subsequent waves; these cases were not removed from the cohort permanently.

Recruiting hospitals were required to keep a screening $\log$, which was returned to the BRIGHTLIGHT team by $95(87 \%)$ hospitals when recruitment ended. Of the
2900 young people who had been screened, $429(15 \%)$ were reported as not being eligible and 1877 (65\%) were eligible to participate. No details were provided for the 
remaining 594 (20\%). Only 426 (23\%) of those eligible had refused to participate, which was lower than the $35 \%$ we had anticipated and accounted for. ${ }^{8}$ Of the $15 \%$ recorded as being ineligible, just over half $(225,52 \%)$ had either no reason recorded or appeared to have been deemed to be ineligible incorrectly.

Data were obtained from NCRAS for young people diagnosed in the same time period, who were potentially eligible, that is, alive 6 months after diagnosis and place of residence was not linked to a prison postcode. A total of 5953 young people were diagnosed with cancer between July 2012 and December 2014, of whom 5835 (98\%) were potentially eligible to participate (109 young people died within 6 months of diagnosis so were assumed to be too sick to be approached and 9 were in prison); 1114 (19\%) appeared in the BRIGHTLIGHT cohort.

Clinical and NHS data were available for all 1114 young people. Of these, $830(75 \%)$ completed the wave 1 survey (figure 2). In total, 163 (20\%) participated once, 186 (22\%) twice, 195 (24\%) completed three, 173 (21\%) completed four and 113 (14\%) took part in every wave.

Non-participants were similar in age and ethnicity to those in the BRIGHTLIGHT cohort, but there were differences in gender (a lower proportion of males in non-participants) and inclusion by tumour type (a greater proportion of young people with leukaemia and lymphoma, germ cell tumours and bone tumours compared with non-participants but lower representation of brain tumours, skin cancers and carcinomas) (table 3).

Of the 1114 young people in the BRIGHTLIGHT cohort, $618(55 \%)$ were men, mean age at diagnosis was 20.13 years (SD 3.28) and 936 (86\%) identified themselves as white. Lymphoma was the most common cancer type $(\mathrm{n}=350 ; 31 \%)$, followed by germ cell tumours $(\mathrm{n}=212 ; 19 \%)$ and leukaemia $(\mathrm{n}=145 ; 13 \%)$ (table 3$)$. Table 4 details the sociodemographic and clinical characteristics of the BRIGHTLIGHT cohort. There was an even distribution across socioeconomic groups. Most were single $(\mathrm{n}=606 ; 84 \%)$ and employed or in education $(\mathrm{n}=531 ; 64 \%)$. Systemic anticancer therapy was the most common form of treatment, which was used for 880 $(79 \%)$. Thirty $(3 \%)$ young people received no treatment, just active monitoring. The clinical processes that were most frequently documented in the clinical records were MDT communication $(n=1037 ; 97 \%)$, cancer stage or prognostic group $(\mathrm{n}=1015 ; 94 \%)$, histology $(\mathrm{n}=974 ; 91 \%)$ and initial treatment plan $(n=974 ; 91 \%)$. One hundred and sixty-seven (20\%) young people reported having a prediagnosis long-term condition.

A total of $124(11 \%)$ young people in the BRIGHTLIGHT cohort died before 31 December 2016. Results from Cox regression indicate that a survival benefit for non-BRIGHTLIGHT patients was maintained even after adjustment for age, gender, ethnicity and type of cancer; the risk of death was $34 \%$ higher for those in the BRIGHTLIGHT cohort compared with those not in the cohort (figure 3; HR estimate 1.34 [95\% CIs 1.09 to 1.68], $\mathrm{p}=0.01$; table 5 ). There was no evidence that survival of cohort participants compared with non-participants differed by cancer type ( $p$ value for interaction: $p=0.12$ ).

A summary of patient-reported outcomes recorded at wave 1 are presented in table 6 . Mean total quality of life, physical and emotional domain scores were $<69.7$ indicating that, on average, young people had some impairment to quality of life shortly after diagnosis. ${ }^{48}$ This is particularly notable in terms of physical scores where the average was significantly below the threshold, by more than 10 points, for a clinically important difference. ${ }^{49} 50$ Forty per cent of young people could be classified as 'cases' for anxiety and $22 \%$ for depression (borderline to severe). ${ }^{51}$ Young people reported high levels of support from friends (Multi-dimensional Scale of Perceived Social Support cut-off $>5$ ) and moderate support from family and significant others (score 3-5). ${ }^{52}$ The Brief Illness Perception Scale results indicate that young people felt cancer had a moderate effect on their life, but they perceived that treatment was extremely helpful. They perceived themselves as having experienced a moderate number of symptoms and believed they had a good understanding of their cancer. The majority rated their satisfaction with care as being excellent/good $(\mathrm{n}=777 ; 94 \%)$. Those aged 19-24 years seemed to have better physical and psychosocial quality of life compared with those aged 13-18 years at diagnosis. This older age group also reported more anxiety, lower social support and better perceived personal control but lower perceived emotional representation and concerns. According to diagnosis, young people with a solid tumour had better physical scores, perceptions of consequences and identity but less support from friends than those with a blood cancer. Finally, there was a noticeable trend for better total quality of life, physical and psychosocial scores for those with less severe disease and worse emotional score for the intermediate severity group. Young people categorised by the BRIGHTLIGHT Severity of Illness Index as having less severe disease had better perceived consequences and identity but satisfaction with care was highest in those with the most severe disease.

\section{DISCUSSION}

The BRIGHTLIGHT cohort is the first national, prospectively recruited cohort of TYAs with cancer. We are able to examine in detail the complexity associated with place of care, experience and outcome. This is made possible through the use of linked data from multiple sources, so unlike other cohorts that rely solely on patient-reported outcomes ${ }^{34}{ }^{47}$ or clinical data, ${ }^{32}$ a more comprehensive evaluation can be derived. Using national mandatory NHS datasets, we have been able to calculate a more robust measure of time spent in specialist TYA care. Other data sources, such as secondary analysis of the National Cancer Patient Experience data, are based on TYA PTC code at the time of participation, ${ }^{53}$ as such this reflects a single point in time and does not reflect experiences and outcomes for those who have exposure to both specialist and non-specialist 
Table 3 Comparison of characteristics of participants and non-participants

\begin{tabular}{|c|c|c|c|c|c|}
\hline & $\mathbf{N}$ & BRIGHTLIGHT cohort & $\mathbf{N}$ & Non-participants & P value* \\
\hline \multicolumn{6}{|l|}{ Age at diagnosis (years) } \\
\hline Mean (SD) & 1114 & $20.13(3.28)$ & 4721 & $19.94(3.33)$ & 0.08 \\
\hline Median (IQR) & & $20.64(17.58,22.95)$ & & $21(17,23)$ & \\
\hline \multicolumn{6}{|l|}{ Gender, n (\%) } \\
\hline Male & 1114 & $618(55)$ & 4721 & $2213(47)$ & $<0.0001$ \\
\hline Female & & $496(45)$ & & 2508 (53) & \\
\hline \multicolumn{6}{|l|}{ Ethnicity n (\%) } \\
\hline White & 1085 & $936(86)$ & 4316 & $3643(84)$ & 0.002 \\
\hline Asian & & $82(8)$ & & $288(7)$ & \\
\hline Black & & $22(2)$ & & $156(4)$ & \\
\hline Chinese & & $4(<1)$ & & $34(<1)$ & \\
\hline Mixed & & $26(2)$ & & $74(2)$ & \\
\hline Other & & $15(1)$ & & $121(3)$ & \\
\hline \multicolumn{6}{|l|}{ Type of cancer, n (\%)† } \\
\hline Leukaemia & 1114 & $145(13)$ & 4721 & $300(6)$ & $<0.0001$ \\
\hline Lymphoma & & $350(31)$ & & $781(17)$ & \\
\hline CNS & & $46(4)$ & & $735(16)$ & \\
\hline Bone & & $102(9)$ & & $177(4)$ & \\
\hline Sarcomas & & $78(7)$ & & $207(4)$ & \\
\hline Germ cell & & $212(19)$ & & $504(11)$ & \\
\hline Skin & & $45(4)$ & & 709 (15) & \\
\hline Carcinoma (not skin) & & $125(11)$ & & $1210(26)$ & \\
\hline Miscellaneous specified & & $9(<1)$ & & $55(1)$ & \\
\hline Unspecified malignant & & $2(<1)$ & & $43(1)$ & \\
\hline \multicolumn{6}{|c|}{ Geographical location, n (\%)‡ } \\
\hline Birmingham & 1114 & $155(14)$ & 4618 & $459(10)$ & $<0.0001$ \\
\hline Bristol & & $116(10)$ & & $351(8)$ & \\
\hline Cambridge & & $23(2)$ & & $276(6)$ & \\
\hline Manchester & & $103(9)$ & & $391(8)$ & \\
\hline Merseyside & & $42(4)$ & & $239(5)$ & \\
\hline East Midlands & & 135 (12) & & $278(6)$ & \\
\hline Leeds & & $106(10)$ & & $254(6)$ & \\
\hline Newcastle & & $59(5)$ & & $305(7)$ & \\
\hline Oxford & & $19(2)$ & & 249 (5) & \\
\hline London (south) & & $77(7)$ & & $668(14)$ & \\
\hline Sheffield & & 37 (3) & & $174(4)$ & \\
\hline Southampton & & $83(8)$ & & $221(5)$ & \\
\hline London (north) & & 159 (14) & & 753 (16) & \\
\hline
\end{tabular}

${ }^{*} \mathrm{P}$ values from $\chi^{2}$ tests and $\mathrm{t}$-tests as appropriate.

†Based on the Birch classification. ${ }^{11}$

$\ddagger$ Hospitals mapped to the multidisciplinary team at the teenage and young adult principal treatment centre they were linked to.

CNS, central nervous system.

care. Measuring exposure to a TYA PTC through analysis of HES data has enabled a more objective exposure variable to be developed. Similarly, defining severity of cancer through prognosis for survival alone does not reflect the symptom/treatment burden of disease and the impact this has on quality of life during treatment and recovery. Systematically defining prognosis alongside symptom and treatment burden provides a more 
Table 4 Sociodemographic and clinical characteristics of the BRIGHTLIGHT cohort at wave 1

\begin{tabular}{|c|c|c|}
\hline Characteristic & Number & $\%$ \\
\hline \multicolumn{3}{|l|}{ Socioeconomic status (IMD quintile) $(n=1088)$} \\
\hline 1 - most deprived & 250 & 23 \\
\hline 2 & 194 & 18 \\
\hline 3 & 209 & 19 \\
\hline 4 & 230 & 21 \\
\hline 5 - least deprived & 205 & 19 \\
\hline \multicolumn{3}{|l|}{ Marital status $(n=725)$} \\
\hline Married/civil partnership & 26 & 4 \\
\hline Cohabiting & 93 & 13 \\
\hline Single/divorced & 606 & 84 \\
\hline \multicolumn{3}{|l|}{ Current status $(n=830)$} \\
\hline Working full/part time & 257 & 31 \\
\hline In education & 274 & 33 \\
\hline Other work (apprentice/intern/voluntary) & 17 & 2 \\
\hline Unemployed & 31 & 4 \\
\hline Long term sick & 126 & 15 \\
\hline Not seeking work & 125 & 15 \\
\hline
\end{tabular}

Length of inpatient stay over 12 months $(n=1070)$ days

$\begin{array}{lll}\text { Median (IQR) } & 25 & 9 \text { to } 74\end{array}$

Treatment $(n=1114)^{\star}$

$\begin{array}{lcl}\text { Systemic anticancer therapy } & 880 & 79 \\ \text { Radiotherapy } & 324 & 29 \\ \text { Surgery } & 551 & 50 \\ \text { Active monitoring } & 30 & 3 \\ \text { Transplant (stem cell or bone marrow) } & 28 & 3\end{array}$

Severity of illness $(n=1114)$

\begin{tabular}{lll} 
Least & 611 & 55 \\
Intermediate & 254 & 23 \\
\hline Most & 249 & 22
\end{tabular}

Clinical processes of care (documentation available in clinical records)

\begin{tabular}{lrc} 
Histological diagnosis $(\mathrm{n}=1072)$ & 974 & 91 \\
Molecular diagnosis $(\mathrm{n}=737) \dagger$ & 258 & 35 \\
Cancer stage or prognostic group $(\mathrm{n}=1078)$ & 1015 & 94 \\
\hline Initial treatment plan $(\mathrm{n}=1071)$ & 974 & 91 \\
MDT communication $(\mathrm{n}=1074)$ & 1037 & 97 \\
$\begin{array}{l}\text { Assessment by supportive care services } \\
(\mathrm{n}=1057)\end{array}$ & 563 & 53 \\
Fertility being discussed $(\mathrm{n}=1063)$ & 693 & 65 \\
\hline Consideration into a clinical trial $(\mathrm{n}=1057)$ & 676 & 64 \\
\hline
\end{tabular}

${ }^{*} \mathrm{~N}$ greater than 1114 reflects multiple treatment modalities for some diagnoses.

tWhere relevant, indicated as not relevant in 320 .

CNS, central nervous system; IMD, Index of Multiple deprivation.

nuanced measure and is a better reflection of the severity of illness.

Selecting the study design to evaluate TYA cancer services across England was challenging as services were already in place and, in some regions of the country, long established. There was also wide variation in implementing the

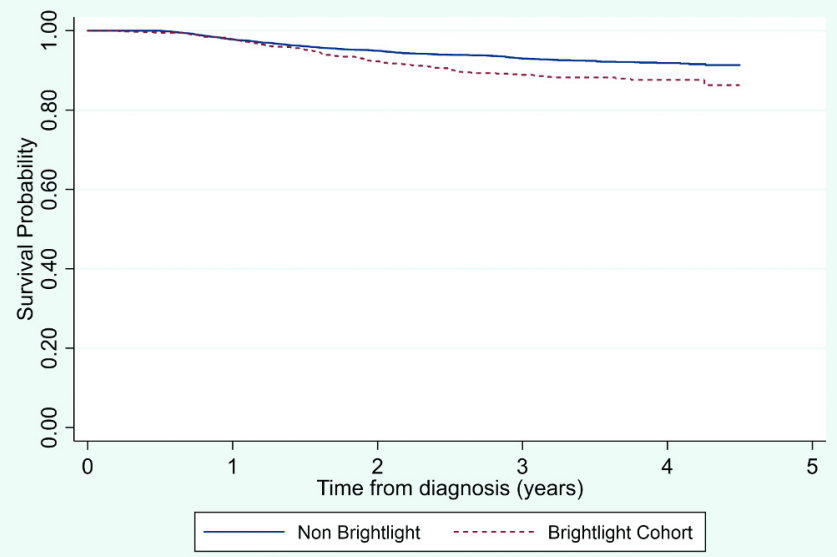

Figure 3 Comparison of survival between participants in the cohort and non-participant.

NICE Guidance ${ }^{1}$ according to local need and pre-existing resources, resulting in services at PTCs not being identical. The decision to establish a cohort was made on the basis that it is suited for investigating rare exposures, allows examination of multiple outcomes for the defined exposure (to specialist care) and would enable us to gather data regarding sequence of events, with the potential to assess causality. The main limitation of the cohort is we only recruited a fifth of the population who were eligible to participate. Variation in diagnosis and severity between those in the cohort receiving different level of PTC care reduces the potential to assess causality.

Cohort studies are acknowledged to be challenging to establish and maintain, especially in rare conditions due to the requirement for large numbers of subjects, potential for selection bias and the challenges associated with subject retention. ${ }^{54-57}$ We anticipated that participation might favour those who were less unwell or had a better prognosis. The inclusion of significant numbers with tumours associated with poorer prognosis such as bone tumours and the inferior survival of the cohort go against this. One of the aims of the BRIGHTLIGHT cohort was to evaluate socioeconomic

Table 5 Comparison of survival between participants in the cohort and non-participants*

Estimated cumulative survival probabilities by year from diagnosis $(95 \% \mathrm{Cl})$

\begin{tabular}{lll}
\hline & Non-participants & BRIGHTLIGHT cohort \\
\hline 1 year & $0.98(0.97$ to 0.98$)$ & $0.98(0.97$ to 0.99$)$ \\
2years & $0.95(0.94$ to 0.96$)$ & $0.92(0.91$ to 0.94$)$ \\
3years & $0.93(0.92$ to 0.94$)$ & $0.89(0.87$ to 0.91$)$ \\
4 years & $0.92(0.91$ to 0.93$)$ & $0.88(0.85$ to 0.90$)$ \\
\hline
\end{tabular}

Log rank test $p$ value $<0.0001$.

*Non-participants were young people diagnosed in the same time frame as the BRIGHTLIGHT cohort identified by the National Cancer Registration and Analysis Service who were not part of BRIGHTLIGHT. 


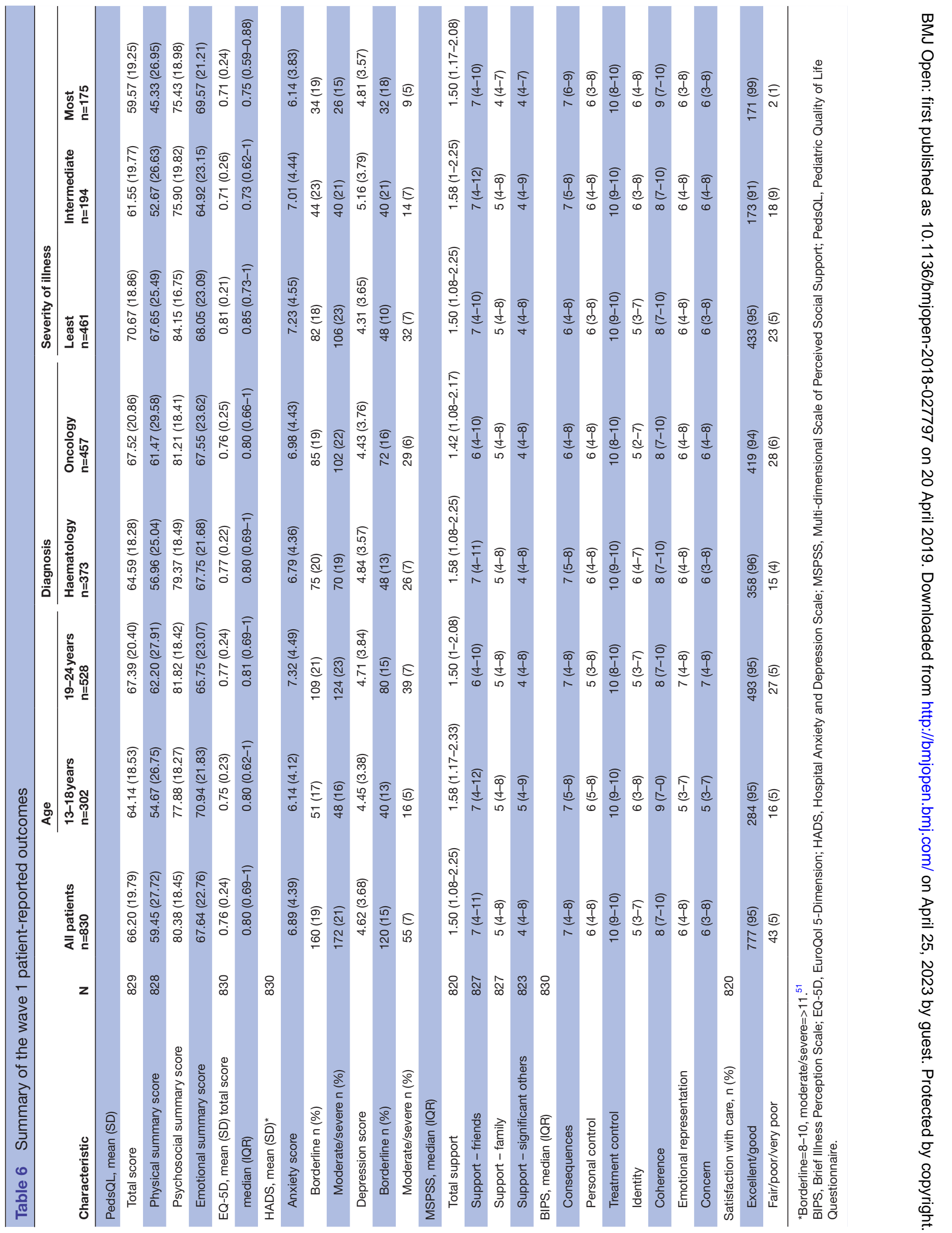


variation in access to specialist care. A comparison of IMD quintile between those who were and were not recruited have enabled us to assess whether there was bias in recruitment according to difference socioeconomic groups; however, these data were not available but warrant exploration in the future. Our experience of recruitment points to the value of maintaining accurate screening logs and seeking mechanisms to complement the intelligence from local teams about change of status of participants such as death or change of address.

Our experience highlights the value of patient and public participation in research. We have described earlier in the paper the involvement young people had from study inception to dissemination. In total, more than 1200 young people have been involved in BRIGHTLIGHT as part of the research process, almost the same number as those recruited. We believe this has positively influenced the rates of participation, ways in which young people were approached and methods of data collection, and doubled the retention rate at wave $3{ }^{7}$

This population is known to have lower involvement in clinical trials in comparison with children and older adults, ${ }^{22} 58$ yet there have been no targeted interventions developed to improve recruitment. ${ }^{59}$ We have reported that to optimise recruitment to clinical trials, what we have identified as 'the 5 A's' need to be addressed, namely availability, accessibility, awareness, appropriateness and acceptability. ${ }^{58}$ We have identified factors that young people feel are acceptable for accessing research ${ }^{8}$ and for continuing their involvement in a study. ${ }^{7}$ We have also identified that the networked structures for facilitating recruitment into cancer research in England may not be optimal for the recruitment of young people. ${ }^{41}$ The impact of not having an optimal research network was made apparent through BRIGHTLIGHT, as it was the first national study in this population. Ways to overcome this challenge are currently being explored by the NIHR.

A potential limitation of the BRIGHTLIGHT cohort study is the outcome measures that were selected to be included in the survey. Traditionally outcome measures are developed for children less than 18 years or adults older than 18 years. Our population crossed both age groups so there were limited measures validated for use in this population. Our measure of quality of life, the PedsQL, has been validated for use in adolescence and adulthood ${ }^{60}$ and has been used often in TYA cancer studies. ${ }^{3461-64}$ The other measures, outlined in table 1, had no formal psychometric testing specifically in a TYA cancer population. However, these have been used extensively in studies in young people with and without cancer, ${ }^{65-71}$ so we are confident the results reflect a consistent measure of each construct but warrants further exploration of the data in the future.

\section{FUTURE PLANS}

The BRIGHTLIGHT cohort was originally designed to evaluate short-term outcomes, from early after diagnosis to 3 years after diagnosis, over five time points. Data collection for wave 5 ended in February 2018, with results for the four key objectives anticipated to be available by the end of 2018. As noted earlier, the study has generated a large quantity of data, and with the recent completion of a James Lind Alliance Priority Setting Partnership exercise for TYA exercise (http:/ / www.ncri.org.uk/ncri-blog/ top-10-research-priorities-for-teenage-and-young-adultcancer-identified/), there is the opportunity to address some of the unanswered questions with the BRIGHTLIGHT cohort. This opportunity has already been realised to contribute evidence to improvements in early diagnosis. ${ }^{19}$ In line with NIHR guidance, patient-reported outcome data from the cohort will be made available to external researchers on acceptance of the final report in the NIHR Journal Library. Details of how to apply will be made available on the website (www.brightlightstudy. com).

The philosophy of specialist TYA cancer care is to provide optimal cancer treatment alongside the developmentally sensitive care that enables young people to achieve their life goals (eg, education, employment and relationships) during treatment and beyond. BRIGHTLIGHT will evaluate this in the short-term but longer term follow-up may be valuable to explore whether the model of care delivery influences these outcomes later in life. We are now planning a 10-year follow-up study to assess the long-term impacts. We also acknowledge that similar to other studies quantifying care using NHS data, ${ }^{5372}$ the measure of specialist care may lack discrimination, not least because it assumes that all TYA PTCs and other places of care are equal. Additional to the cohort, a case study was conducted to understand the culture of TYA cancer care. ${ }^{3}$ There is the potential to synthesise the qualitative findings from the case study with the quantitative data from the cohort to develop a more detailed and sensitive metric to define specialist TYA cancer care. Ultimately, the data generated by the cohort and BRIGHTLIGHT will provide new information on cancer in young people and determine if access to a PTC adds value. The relationships between specialist care and outcomes have previously been unclear. Findings will inform intervention and policy efforts to improve outcomes for young people with cancer.

\section{Author affiliations}

${ }^{1}$ Cancer Clinical Trials, University College Hospitals NHS Foundation Trust, London, UK

${ }^{2}$ Department of Oncology, University College London Hospitals NHS Foundation Trust, London, UK

${ }^{3}$ Department of Statistical Science, University College London, London, UK

${ }^{4}$ Department of Biomedicine, Biotechnology and Public Health, University of Cadiz, Cádiz, Spain

${ }^{5}$ School of Medicine, University of Leeds, Leeds, UK

${ }^{6}$ Department of Applied Health Research, University College London, London, UK

${ }^{7}$ Wessex Teenage and Young Adult Cancer Service, University Hospital

Southhamptom, Southampton, UK

${ }^{8}$ Division of Cancer Sciences, University of Manchester, Manchester, UK

${ }^{9}$ ORCHID, Great Ormond Street Hospital For Children NHS Trust, London, UK

${ }^{10}$ School of Health Sciences, University of Surrey, Guildford, UK

${ }^{11}$ Institute of Epidemiology \& Health, University College London, London, UK 
${ }^{12}$ Leeds Insitute of Molecular Medicine, University of Leeds, Leeds, UK

Acknowledgements We would like to thank the members of our Young Advisory Panel (Zeena Beale, Ciaran Fenton, Emily Freemantle, Laura Haddad, Steph Hammersley, Amy Lang, Joshua Lerner, Tanya Loughlin, Maria Onasanya, Steph Still, Poppy Richards, Amy Riley, Freya Voss, J J Wheeler and Antonia Young), the 1114 young people who consented to participate in BRIGHTLIGHT and ex-members of the team who have contributed to study management (Catherine 0'Hara, Anita Solanki, Natasha Aslam and Zuwena Fox). We would also like to thank the following for all their support with recruitment to BRIGHTLIGHT: the National Cancer Research Institute, especially Dr Eileen Loucaides and the Secretariat; Matt Seymour, Matt Cooper and Karen Poole at the former National Cancer Research Network; Maria Khan and Sabrina Sandhu (North West Knowledge Intelligence Team); TYAC; Teenage Cancer Trust; CLIC Sargent; Ipsos MORI; Quality Health and the research teams at 109 NHS Trusts in England who opened BRIGHTLIGHT to recruitment. Principal investigators agreeing to be acknowledged for their contribution to BRIGHTLIGHT recruitment: Claire Hemmaway, Barking, Havering and Redbridge Hospitals NHS Trust; Anita Amadi, Barnet and Chase Farm Hospitals NHS Trust; Keith Elliott, Barnsley Hospital NHS Foundation Trust; Leanne Smith, Blackpool, Fylde and Wyre Hospitals NHS Trust; Shirley Cocks, Bolton NHS Foundation Trust; Victoria Drew, Bradford Teaching Hospitals NHS Foundation Trust; Elizabeth Pask, Central Manchester University Hospitals NHS Foundation Trust; Anne Littley, Central Manchester University Hospitals NHS Foundation Trust; Mark Bower, Chelsea and Westminster Hospital NHS Trust; Scott Marshall, City Hospitals Sunderland NHS Foundation Trust; Lorna Dewar, Colchester Hospital University NHS Trust; Nnenna Osuji, Croydon Health Services NHS Trust; David Allotey, Derby Hospitals NHS Foundation Trust; Karen Jewers, East Lancashire Hospitals NHS Trust; Asha Johny, Gloucestershire Hospitals NHS Foundation Trust; Nicola Knightly, Great Western Hospitals NHS Foundation Trust; Robert Carr, Guy's \& St Thomas' Hospital NHS Foundation Trust;Alison Milne, Hampshire Hospitals NHS Foundation Trust; Claire Hall, Harrogate and District NHS Foundation Trust; James Bailey, Hull and East Yorkshire Hospitals NHS Trust; Christine Garlick, Ipswich Hospital NHS Foundation Trust; Alison Brown, Isle of Wight Healthcare NHS Trust; Carolyn Hatch, Lancashire Teaching Hospitals NHS Foundation Trust; Vivienne E Andrews, Medway NHS Foundation Trust; Sara Greig, Milton Keynes Hospital NHS Foundation Trust; Jennifer Wimperis, Norfolk and Norwich University Hospital NHS Trust; Suriya Kirkpatrick, North Bristol NHS Trust; Jonathan Nicoll, North Cumbria University Hospitals NHS Trust; Ivo Hennig, Nottingham University Hospitals NHS Trust; Karen Sherbourne, Oxford Radcliffe Hospital NHS Trust; Clare Turner, Plymouth Hospitals NHS Trust; Claire Palles-Clark, Royal Surrey County Hospital NHS Trust; Christine Cox, Royal United Hospital Bath NHS Trust; Yeng Ang, Salford Royal NHS Foundation Trust; Jonathan Cullis, Salisbury NHS Foundation Trust; Daniel Yeomanson, Sheffield Children's NHS Foundation Trust; Ruth Logan, Sheffield Teaching Hospitals NHS Foundation Trust; Deborah Turner, South Devon Healthcare NHS Trust; Dianne Plews, South Tees Hospitals NHS Trust; Juliah Jonasi, Southend University Hospital NHS Foundation Trust; Ruth Pettengell, St George's Healthcare NHS Trust; Kamal Khoobarry, Surrey \& Sussex Healthcare NHS Trust; Angela Watts, The Dudley Group of Hospitals NHS Foundation Trust; Louise Soanes, The Royal Marsden NHS Foundation Trust; Claudette Jones, The Royal Orthopaedic Hospital NHS Trust; Michael Jenkinson, The Walton Centre for Neurology and Neurosurgery NHS Trust; Nicky Pettitt, University Hospital Birmingham NHS Foundation Trust; Vijay Agarwal, University Hospital Birmingham NHS Foundation Trust; Beth Harrison, University Hospitals Coventry and Warwickshire NHS Trust; Fiona Miall, University Hospitals of Leicester NHS Trust; Gail Wiley, University Hospitals of Morecambe Bay NHS Trust; Lynda Wagstaff, Walsall Hospitals NHS Trust; Fiona Smith, West Hertfordshire Hospitals NHS Trust; Sarah Janes, Western Sussex NHS Trust; Serena Hillman, Weston Area Health NHS Trust; Christopher Zaborowski, Yeovil District Hospital NHS Foundation Trust. Data for this study are based on information collected and quality assured by the PHENational Cancer Registration and Analysis Service. Access to the data was facilitated by the PHE Office for Data Release. The Quality of Life study described in this paper was carried out using the PedsQL, developed by Dr James W Varni.

Contributors RMT, LAF, JB, DPS, SM, RF, LH, MGM, FG, RR and JSW were involved in developing the protocol. RMT coordinated the running of the study and was responsible for data acquisition. JB, JA-G, RMT, LAF, SM, RF, DPS and JSW contributed to the analysis. RMT, LAF, JB and JSW drafted the manuscript. All authors critically revised and approved the final manuscript.

Funding This paper presents independent research funded by the National Institute for Health Research (NIHR) under its Programme Grants for Applied Research Programme (Grant Reference Number RP-PG-1209-10013). The BRIGHTLIGHT Team acknowledges the support of the NIHR, through the Cancer
Research Network and support from University College London Hospitals Biomedical Research Centre. LF and LH are funded by Teenage Cancer Trust, and RR was (in part) supported by the NIHR Collaboration for Leadership in Applied Health Research and Care North Thames at Bart's Health NHS Trust. None of the funding bodies have been involved with study concept, design or decision to submit the manuscript.

Disclaimer The views expressed are those of the author(s) and not necessarily those of the NHS, the NIHR, the Department of Health or Social Care or Teenage Cancer Trust.

Competing interests None declared.

Patient consent for publication Not required.

Ethics approval The study was approved by London Bloomsbury NHS Research Ethics Committee (reference L0/11/1718). Approval by the Secretary of State under Regulation 5 of the Health Services (Control of Patient Information) Regulation 2002 was obtained from the Health Research Authority Confidentiality Advisory Group (reference ECC 8-05(d)/2011) to access the CWT dataset, Hospital Episode Statistic data and data from the National Cancer Registration and Analysis Service.

Provenance and peer review Not commissioned; externally peer reviewed.

Data sharing statement Further details of the BRIGHTLIGHT programme of work is available through the study website (www.brightlightstudy.com). Data that are not held under licence with Public Health England or NHS Digital will be available from late 2018 when the primary analysis is complete. We welcome collaboration; for general data sharing enquiries, please contact RMT (rtaylor13@nhs.net).

Open access This is an open access article distributed in accordance with the Creative Commons Attribution Non Commercial (CC BY-NC 4.0) license, which permits others to distribute, remix, adapt, build upon this work non-commercially, and license their derivative works on different terms, provided the original work is properly cited, appropriate credit is given, any changes made indicated, and the use is non-commercial. See: http://creativecommons.org/licenses/by-nc/4.0/.

\section{REFERENCES}

1. National Institute for Health and Care Excellence. Guidance on cancer services: improving outcomes in children and young people with cancer. NICE, London. 2005 https://www.nice.org.uk/guidance/ csg7/resources/improving-outcomes-in-children-and-young-peoplewith-cancer-update-773378893 (Accessed 09 Sep 16).

2. Vindrola-Padros C, Taylor RM, Lea S, et al. Mapping Adolescent Cancer Services: How Do Young People, Their Families, and Staff Describe Specialized Cancer Care in England? Cancer Nurs 2016;39:358-66.

3. Lea S, Taylor RM, Martins A, et al. Conceptualizing age-appropriate care for teenagers and young adults with cancer: a qualitative mixedmethods study. Adolesc Health Med Ther. In Press. 2018:9:149-66.

4. Taylor RM, Feltbower RG, Aslam N, et al. Modified international e-Delphi survey to define healthcare professional competencies for working with teenagers and young adults with cancer. BMJ Open 2016;6:e011361.

5. Taylor RM, Mohain J, Gibson F, et al. Novel participatory methods of involving patients in research: naming and branding a longitudinal cohort study, BRIGHTLIGHT. BMC Med Res Methodol 2015;15:20.

6. Taylor RM, Fern L, Whelan J, et al. "Your place or mine?" priorities for a specialist teenage and young adult (tya) cancer unit: disparity between tya and professional perceptions. J Adolesc Young Adult Oncol 2011;1:145-51.

7. Taylor RM, Aslam N, Lea S, et al. Optimizing a retention strategy with young people for brightlight, a longitudinal cohort study examining the value of specialist cancer care for young people. J Adolesc Young Adult Oncol 2017;6:459-69.

8. Taylor RM, Solanki A, Aslam N, et al. A participatory study of teenagers and young adults views on access and participation in cancer research. Eur J Oncol Nurs 2016;20:156-64.

9. Fern L, Taylor RM, Whelan J, et al. 'The art of age appropriate care': using participatory research to describe young people's experience of cancer. Cancer Nursing 2013;36:E27-38.

10. Cancer Research UK. Teenagers and Young Adult Cancer, Cancer Statistics Key Stats. Cancer Research UK, London 2015.

11. Birch JM, Pang D, Alston RD, et al. Survival from cancer in teenagers and young adults in England, 1979-2003. Br J Cancer 2008;99:830-5.

12. Whelan J, Fern L. Cancer in adolescence: incidence and policy issues. Kelly D, Gibson F, eds. Oxford: Blackwell, 2008. 
13. Morgan S, Davies S, Palmer S, et al. Sex, drugs, and rock ' $n$ ' roll: caring for adolescents and young adults with cancer. J Clin Oncol 2010;28:4825-30.

14. Department for Education aS. Youth matters, 2005.

15. Ries L, Trama A, Nakata K, et al. Cancer incidence, survival, and mortality among adolescents and young adults. In: Bleyer A, Barr R, Ries L, eds. Cancer in adolescents and young adults. Switzerland: Springer International Publishing, 2017:7-42. et al.

16. Stark $D$, Bielack $S$, Brugieres $L$, et al. Teenagers and young adults with cancer in Europe: from national programmes to a European integrated coordinated project. Eur J Cancer Care 2016;25:419-27.

17. Thomas DM, Seymour JF, O'Brien T, et al. Adolescent and young adult cancer: a revolution in evolution? Intern Med J 2006;36:302-7.

18. Hollis R, Morgan S. The adolescent with cancer-at the edge of noman's land. Lancet Oncol 2001;2:43-8.

19. Herbert A, Lyratzopoulos G, Whelan J, et al. Diagnostic timeliness in adolescents and young adults with cancer: a cross-sectional analysis of the BRIGHTLIGHT cohort. Lancet Child Adolesc Health 2018;2:180-90.

20. Tricoli JV, Blair DG, Anders CK, et al. Biologic and clinical characteristics of adolescent and young adult cancers: Acute lymphoblastic leukemia, colorectal cancer, breast cancer, melanoma, and sarcoma. Cancer 2016;122:1017-28.

21. Albritton KH, Eden T. Access to care. Pediatr Blood Cancer 2008:50:1094-8.

22. Fern L, Davies S, Eden T, et al. Rates of inclusion of teenagers and young adults in England into National Cancer Research Network clinical trials: report from the National Cancer Research Institute (NCRI) Teenage and Young Adult Clinical Studies Development Group. Br J Cancer 2008;99:1967-74.

23. Fern LA, Whelan JS. Recruitment of adolescents and young adults to cancer clinical trials-international comparisons, barriers, and implications. Semin Oncol 2010;37:e1-8.

24. Ferrari $\mathrm{A}$, Montello $\mathrm{M}$, Budd $\mathrm{T}$, et al. The challenges of clinical trials for adolescents and young adults with cancer. Pediatr Blood Cancer 2008;50:1101-4.

25. Kondryn HJ, Edmondson CL, Hill JW, et al. Treatment non-adherence in teenage and young adult cancer patients: a preliminary study of patient perceptions. Psychooncology 2009;18:1327-32.

26. Butow P, Palmer S, Pai A, et al. Review of adherence-related issues in adolescents and young adults with cancer. $\mathrm{J}$ Clin Oncol 2010;28:4800-9.

27. Tsangaris $\mathrm{E}$, Johnson J, Taylor $\mathrm{R}$, et al. Identifying the supportive care needs of adolescent and young adult survivors of cancer: a qualitative analysis and systematic literature review. Support Care Cancer 2014;22:947-59.

28. Bibby $\mathrm{H}$, White $\mathrm{V}$, Thompson $\mathrm{K}$, et al. What are the unmet needs and care experiences of adolescents and young adults with cancer? a systematic review. J Adolesc Young Adult Oncol 2017;6:6-30.

29. Marshall S, Grinyer A, Limmer M. The 'lost tribe' reconsidered: teenagers and young adults treated for cancer in adult settings in the UK. Eur J Oncol Nurs 2018;33:85-90.

30. Olsson M, Jarfelt M, Pergert P, et al. Experiences of teenagers and young adults treated for cancer in Sweden. Eur J Oncol Nurs 2015;19:575-81.

31. Zebrack B, Kent EE, Keegan TH, et al. "Cancer sucks," and other ponderings by adolescent and young adult cancer survivors. $J$ Psychosoc Oncol 2014;32:1-15.

32. Baxter NN, Daly C, Gupta S, et al. The initiative to maximize progress in adolescent and young adult cancer therapy (IMPACT) cohort study: a population-based cohort of young Canadians with cancer. BMC Cancer 2014:14:805.

33. Cassano J, Nagel K, O'Mara L. Talking with others who "just know": perceptions of adolescents with cancer who participate in a teen group. J Pediatr Oncol Nurs 2008;25:193-9.

34. Smith AW, Bellizzi KM, Keegan THM, et al. Health-related quality of life of adolescent and young adult patients with cancer in the United States: the adolescent and young adult health outcomes and patient experience study. Journal of Clinical Oncology 2013;31:2136-45.

35. Whelan J, Dolbear C, Mak V, et al. Where do teenagers and young adults receive treatment for cancer? J Public Health 2007;29:178-82.

36. Pollock BH. Where adolescents and young adults with cancer receive their care: does it matter? J Clin Oncol 2007;25:4522-3.

37. Taylor RM, Fern LA, Solanki A, et al. Development and validation of the BRIGHTLIGHT Survey, a patient-reported experience measure for young people with cancer. Health Qual Life Outcomes 2015;13:107.

38. Martins A, Taylor RM, Lobel B, et al. Sex, body image and relationships- information and support needs of adolescents and young adults: BRIGHTLIGHT. J Adolesc Young Adult Oncol 2018;7.

39. Taylor RM, Whelan JS, Gibson F, et al. Involving young people in BRIGHTLIGHT from study inception to secondary data analysis: insights from $10 y e a r s$ of user involvement. Res Involv Engagem 2018;4.

40. O'Hara C, Khan M, McCabe M, et al. Notifications of teenagers and young adults with cancer to a principal treatment centre 2009-2010: National Cancer Intelligence Network, 2013. http://www.ncin.org.uk/ view?rid=2124

41. Kenten C, Martins A, Fern LA, et al. Qualitative study to understand the barriers to recruiting young people with cancer to BRIGHTLIGHT: a national cohort study in England. BMJ Open 2017;7:e01829.

42. Pearce S, Gibson F, Fern L, et al; The 'Essence of Care' for teenagers and young adults with cancer: a national longitudinal study to assess the benefits of specialist care. Phase 1 feasibility and scoping study. London: Teenage Cancer Trust, 2010.

43. Taylor RM, Fern LA, Aslam N, et al. Direct access to potential research participants for a cohort study using a confidentiality waiver included in UK National Health Service legal statutes. BMJ Open 2016;6:e011847.

44. Taylor RM, Pearce S, Gibson F, et al. Developing a conceptual model of teenage and young adult experiences of cancer through metasynthesis. Int J Nurs Stud 2013;50:832-46.

45. Department of Communities and Local Government. The English Index of Multiple Deprivation (IMD) 2015 - Guidance. 2015 https:// assets.publishing.service.gov.uk/government/uploads/system/ uploads/attachment_data/file/464430/English_Index_of_Multiple_ Deprivation_2015_-_Guidance.pdf

46. Husson O, Zebrack BJ. Perceived impact of cancer among adolescents and young adults: Relationship with health-related quality of life and distress. Psychooncology 2017;26:1307-15.

47. Husson O, Zebrack BJ, Block R, et al. Health-related quality of life in adolescent and young adult patients with cancer: a longitudinal study. J Clin Oncol 2017;35:652-9.

48. Varni JW, Burwinkle TM, Seid M, et al. The PedsQL (TM) 4.0 as a pediatric population health measure: Feasibility. reliability and validity, Ambulatory Pediatrics 2003;3:329-41.

49. Fredericks EM, Magee JC, Opipari-Arrigan L, et al. Adherence and health-related quality of life in adolescent liver transplant recipients. Pediatr Transplant 2008;12:289-99.

50. Varni JW, Burwinkle TM, Katz ER, et al. The PedsQL in pediatric cancer: reliability and validity of the pediatric quality of life inventory generic core scales, multidimensional fatigue scale, and cancer module. Cancer 2002:94:2090-106.

51. Stern AF. Questionnaire review: the hospital anxiety and depression scale. Occupational Medicine 2014;64:393-4.

52. Zimet GD, Powell SS, Farley GK, et al. Psychometric characteristics of the multidimensional scale of perceived social support. $J$ Pers Assess 1990;55:610-7.

53. Furness CL, Smith L, Morris E, et al. Cancer patient experience in the teenage young adult population- key issues and trends over time: an analysis of the united kingdom national cancer patient experience surveys 2010-2014. J Adolesc Young Adult Oncol 2017;6:450-8.

54. Booker CL, Harding S, Benzeval M. A systematic review of the effect of retention methods in population-based cohort studies. BMC Public Health 2011;11:249.

55. Cantrell MA, Conte T, Hudson M, et al. Recruitment and retention of older adolescent and young adult female survivors of childhood cancer in longitudinal research. Oncol Nurs Forum 2012;39:483-90.

56. Ely B, Coleman C. Recruitment and retention of children in longitudinal research. J Spec Pediatr Nurs 2007;12:199-202.

57. Hanna KM, Scott LL, Schmidt KK. Retention strategies in longitudinal studies with emerging adults. Clin Nurse Spec 2014;28:41-5.

58. Fern LA, Lewandowski JA, Coxon KM, et al. Available, accessible, aware, appropriate, and acceptable: a strategy to improve participation of teenagers and young adults in cancer trials. Lancet Oncol 2014;15:e341-e350.

59. Fern LA, Taylor RM. Enhancing accrual to clinical trials of adolescents and young adults with cancer. Pediatr Blood Cancer 2018;65:e27233.

60. Varni JW, Limbers CA. The PedsQL 4.0 Generic Core Scales Young Adult Version: feasibility, reliability and validity in a university student population. J Health Psychol 2009;14:611-22.

61. Barrera M, Teall T, Barr R, et al. Health related quality of life in adolescent and young adult survivors of lower extremity bone tumors. Pediatr Blood Cancer 2012;58:265-73.

62. Ewing JE, King MT, Smith NF. Validation of modified forms of the PedsQL generic core scales and cancer module scales for adolescents and young adults (AYA) with cancer or a blood disorder. Qual Life Res 2009;18:231-44.

63. Kumar R, Rodriguez V, Matsumoto JM, et al. Health-related quality of life in children and young adults with post-thrombotic syndrome: results from a cross-sectional study. Pediatr Blood Cancer 2014:61:546-51. 
64. Robert RS, Paxton RJ, Palla SL, et al. Feasibility, reliability, and validity of the Pediatric Quality of Life Inventory ${ }^{\mathrm{TM}}$ generic core scales, cancer module, and multidimensional fatigue scale in long-term adult survivors of pediatric cancer. Pediatr Blood Cancer 2012;59:703-7.

65. Bruwer B, Emsley R, Kidd M, et al. Psychometrlc properties of the multidimensional scale of perceived social support in youth. Compr Psychiatry 2008;49:195-201.

66. Canty-Mitchell J, Zimet GD. Psychometric properties of the Multidimensional Scale of Perceived Social Support in urban adolescents. Am J Community Psychol 2000;28:391-400.

67. Husson O, Prins JB, Kaal SE, et al. Adolescent and young adult (AYA) lymphoma survivors report lower health-related quality of life compared to a normative population: results from the PROFILES registry. Acta Oncol 2017;56:288-94.

68. Juth V, Silver RC, Sender L. The shared experience of adolescent and young adult cancer patients and their caregivers. Psychooncology 2015;24:1746-53.

69. Kaal SEJ, Husson O, van Duivenboden S, et al. Empowerment in adolescents and young adults with cancer: Relationship with healthrelated quality of life. Cancer 2017;123:4039-47.
70. Rothon C, Stansfeld SA, Mathews C, et al. Reliability of self report questionnaires for epidemiological investigations of adolescent mental health in Cape Town, South Africa. J Child Adolesc Ment Health 2011;23:119-28.

71. Thewes B, Kaal SEJ, Custers JAE, et al. Prevalence and correlates of high fear of cancer recurrence in late adolescents and young adults consulting a specialist adolescent and young adult (AYA) cancer service. Support Care Cancer 2018;26:1479-87.

72. Fairley L, Stark DP, Yeomanson D, et al. Access to principal treatment centres and survival rates for children and young people with cancer in Yorkshire, UK. BMC Cancer 2017;17:168.

73. Rabin R, Gudex C, Selai C, et al. From translation to version management: a history and review of methods for the cultural adaptation of the EuroQol five-dimensional questionnaire. Value Health 2014;17:70-6.

74. Zigmond AS, Snaith RP. The hospital anxiety and depression scale. Acta Psychiatr Scand 1983;67:361-70.

75. Broadbent E, Petrie KJ, Main J, et al. The brief illness perception questionnaire. J Psychosom Res 2006;60:631-7. 